\title{
Enhanced Spore Production of Bacillus subtilis Grown in a Chemically Defined Medium
}

\author{
S. M. S. Monteiro1,2, J. J. Clemente1, M. J. T. Carrondo1,2,3, A. E. Cunha' ${ }^{1,2}$ \\ ${ }^{1}$ Instituto de Biologia Experimental e Tecnológica (IBET), Oeiras, Portugal \\ ${ }^{2}$ Instituto de Tecnologia Química e Biológica (ITQB), Oeiras, Portugal \\ ${ }^{3}$ Laboratório de Engenharia Bioquímica, Faculdade de Ciências e Tecnologia, Universidade Nova de Lisboa, \\ Monte da Caparica, Caparica, Portugal \\ Email: cunha@itgb.unl.pt
}

Received 27 March 2014; revised 27 April 2014; accepted 7 May 2014

Copyright @ 2014 by authors and Scientific Research Publishing Inc.

This work is licensed under the Creative Commons Attribution International License (CC BY).

http://creativecommons.org/licenses/by/4.0/

cc) (i) Open Access

\begin{abstract}
Spores of Bacillus subtilis are being used as probiotics and competitive exclusion agents for animal consumption. Commercial production media often include relatively expensive components of animal origin that are a potential source for the presence of adventious agents, therefore undesirable for use in production scale. In this study a new animal-free component, chemically defined medium, was tested for $B$. subtilis spore production. Medium composition was optimized with respect to vitamin composition, carbon, nitrogen and calcium concentrations. A fed-batch bioprocess was developed, being the effect on sporulation of the carbon to nitrogen ratio at the end of the exponential growth phase studied. The developed strategy consisted of an initial and a final batch phase and an intermediate fed-batch phase with the addition of a feeding solution containing glucose and calcium and the addition of a feeding solution of ammonium sulphate, using an exponential and a constant feeding profile, respectively. Using the fed-batch strategy, it was possible to achieve a maximum spore production of $3.6 \times 10^{10} \mathrm{spores} / \mathrm{mL}$, corresponding to a 5 folds increase when compared to the preliminary batch experiments.
\end{abstract}

\section{Keywords}

Bacillus subtilis, Spores, Probiotics, Bioreaction, Fed-Batch

\section{Introduction}

Bacillus subtilis is a gram-positive and endospore-forming bacteria with a potential use as probiotics for feed

How to cite this paper: Monteiro, S.M.S., Clemente, J.J., Carrondo, M.J.T. and Cunha, A.E. (2014) Enhanced Spore Production of Bacillus subtilis Grown in a Chemically Defined Medium. Advances in Microbiology, 4, 444-454.

http://dx.doi.org/10.4236/aim.2014.48049 
supplement in farming industries to promote animal growth as an alternative to the use of antibiotics [1]. The capacity of selected Bacillus strains to produce and secrete large quantities of extracellular enzymes has placed them among the most important industrial enzyme producers [2].

Homogeneous sporulation conditions and precise regulation of growth and sporulation parameters are of great importance for obtaining reproducible and homogeneous batches. A single chemically defined medium allowing both rapid growth and complete Bacillus subtilis sporulation would be valuable [3]. Chemically defined media contain known quantities of only chemically defined ingredients. Defined media include no complex ingredients such as proteins, hydrolysates, animal-derived ingredients, or constituents of unknown composition. The absence of animal-derived components, desirable from a regulatory standpoint due to concerns over BSE/TSE, is a major advantage of chemically defined media. Batch to batch reproducibility is another advantage of using chemically defined media; all components of a defined medium have known chemical structures, which allow for consistent growth of the microorganism in the medium.

For the commercial production of a probiotic, careful selection of carbon and nitrogen sources as well as mineral supplements is necessary for optimum growth and sporulation of the microorganism. In addition, the carbon to nitrogen $(\mathrm{C}: \mathrm{N})$ ratio is also of major importance in the optimization of the medium nutrient supply [4] [5] [6].

The energetic efficiency of microbial growth is significantly reduced in cultures growing under glucose excess compared to cultures growing under glucose limitation [7]. Compared to those with carbon (C) limitation, excess-C cultures exhibit generally high rates of carbon consumption and low yields of biomass and thus have low energetic growth efficiency. Most frequently excess-C cultures in chemostats are limited by other cellular macro elements such as nitrogen $(\mathrm{N})$, phosphorous $(\mathrm{P})$ and potassium [7].

Another factor implicated in spore resistance properties and germination is a small molecule, pyridine-2,6dicarboxylic acid (dipicolinic acid [DPA]). The $\mathrm{Ca}^{2+}$ chelate of DPA (Ca-DPA) is a major constituent of the dormant spore core, accounting for approximately $10 \%$ of the total spore dry weight. [8]. As described by O'Hara and Hageman [9], in chemically defined sporulation medium, cells are strongly dependent on the addition of Calciumions to the medium to achieve maximal sporulation.

In this paper we document the successful use of a fed-batch strategy to improve sporulation of Bacillus subtilis in chemically defined medium. Medium composition was optimised in order to obtain a high yield production of $B$. subtilis spores. The effect of carbon concentration and carbon-to-nitrogen ratio (C:N) as well as their interaction on growth and sporulation of the microorganism were also evaluated at $2 \mathrm{~L}$ bioreactor scale. A fed-batch bioprocess was developed, and feed was started before the complete depletion of the nutrients present in the media, at the middle of the exponential growth phase, thus before starting the sporulation process as described by [10]. The carbon feeding solution was added using an exponential feeding profile obtained from the mass balance equations previously described by [11]. The nitrogen solution was added using a constant feeding profile. The effect of carbon and nitrogen concentration at the end of the feeding phase was studied as published data indicate that the excess of glucose over ammonium minimizes the autolytic tendencies of the cells at the end of the exponential growth phase; the addition of an oxidizable carbon source to starved and lysing cultures prevents this autolysis [12] [13].

\section{Materials and Methods}

\subsection{Strain}

A spore stock of a B. subtilis strain isolated from the broiler gastrointestinal tract (isolate \#210 in [14]) was prepared in chemically defined medium, divided in $1 \mathrm{~mL}$ aliquots and stored with $30 \%$ of glycerol in liquid nitrogen.

\subsection{Culture Media}

Luria-Bertani (LB) medium was used in the measurements of vegetative cell and spore concentrations, its composition being yeast extract $5 \mathrm{~g} \cdot \mathrm{L}^{-1}$, peptone $10 \mathrm{~g} \cdot \mathrm{L}^{-1}$ and $\mathrm{NaCl} 10 \mathrm{~g} \cdot \mathrm{L}^{-1}$. Difco sporulation medium (DSM) was used as a control in shake flask cultivation: bacto nutrient broth $8 \mathrm{~g} \cdot \mathrm{L}^{-1}, \mathrm{KCl} 1 \mathrm{~g} \cdot \mathrm{L}^{-1}$ and $\mathrm{MgSO}_{4} 0.25 \mathrm{~g} \cdot \mathrm{L}^{-1}$, sterilized at $121^{\circ} \mathrm{C}$ for 30 minutes. To $1 \mathrm{~L}$ of this solution, $1 \mathrm{~mL}$ of each of the following filter sterilized solutions were added: $\mathrm{Ca}\left(\mathrm{NO}_{3}\right)_{2} 1 \mathrm{M}, \mathrm{MnCl}_{2} 10 \mathrm{mM}$ and $\mathrm{FeSO}_{4} 1 \mathrm{mM}$. 
Vitamins solution used in the shake flask experiments: Biotin $2 \times 10^{-3} \mathrm{~g} \cdot \mathrm{L}^{-1}$, Folic acid $2 \times 10^{-2} \mathrm{~g} \cdot \mathrm{L}^{-1}$, Piridoxine-HCl $0.1 \mathrm{~g} \cdot \mathrm{L}^{-1}$, Tiamine-HCl $5 \times 10^{-2} \mathrm{~g} \cdot \mathrm{L}^{-1}$, Riboflavin-HCl $5 \times 10^{-2} \mathrm{~g} \cdot \mathrm{L}^{-1}$, Nicotic acid $5 \times 10^{-2} \mathrm{~g} \cdot \mathrm{L}^{-1}$, DL-Calcium pantothenate $5 \times 10^{-2} \mathrm{~g} \cdot \mathrm{L}^{-1}$, Vitamin B12 $1 \times 10^{-3} \mathrm{~g} \cdot \mathrm{L}^{-1}$, p-aminobenzoic acid $5 \times 10^{-2} \mathrm{~g} \cdot \mathrm{L}^{-1}$ and lipoic acid $5 \times 10^{-2} \mathrm{~g} \cdot \mathrm{L}^{-1}$, filter sterilised. $1 \mathrm{~mL}$ of this solution should be added per liter of culture media.

Chemically defined sporulation medium was used for inoculum preparation, batch and fed-batch cultures, its composition being $\mathrm{C}_{6} \mathrm{H}_{8} \mathrm{O}_{7} \cdot \mathrm{H}_{2} \mathrm{O} 3.21 \mathrm{~g} \cdot \mathrm{L}^{-1}, \mathrm{KH}_{2} \mathrm{PO}_{4} 5.95 \mathrm{~g} \cdot \mathrm{L}^{-1}, \mathrm{~K}_{2} \mathrm{HPO}_{4} 1 \mathrm{~g} \cdot \mathrm{L}^{-1}, \mathrm{NaH}_{2} \mathrm{PO}_{4} 2.72 \mathrm{~g} \cdot \mathrm{L}^{-1}$, $\left(\mathrm{NH}_{4}\right)_{2} \mathrm{SO}_{4} 1.07 \mathrm{~g} \cdot \mathrm{L}^{-1}, \mathrm{MgCl}_{2} \cdot 6 \mathrm{H}_{2} \mathrm{O} 1.34 \mathrm{~g} \cdot \mathrm{L}^{-1}$ and $\left(\mathrm{NH}_{4}\right)_{2} \mathrm{HPO}_{4} 2.95 \mathrm{~g} \cdot \mathrm{L}^{-1}$, which was sterilized at $121^{\circ} \mathrm{C}$ for 30 minutes. To $1 \mathrm{~L}$ of this solution the following filter sterilized solutions were added: $10 \mathrm{~mL}$ of salts solution, 2 $\mathrm{mL}$ of $\mathrm{FeCl}_{3} \cdot 6 \mathrm{H}_{2} \mathrm{O} 0.03 \mathrm{M}, 20 \mu \mathrm{L}$ of Tiamine-HCl $1.5 \mathrm{M}$ and $1.45 \mathrm{~mL}$ of $\mathrm{Ca}\left(\mathrm{NO}_{3}\right)_{2} 1 \mathrm{M} .50 \mathrm{~mL}$ of a $400 \mathrm{~g} \cdot \mathrm{L}^{-1}$ solution of glucose sterilized at $121^{\circ} \mathrm{C}$ for 30 minutes were added before $\mathrm{pH}$ adjustment to 7.5 with $\mathrm{NaOH} 5 \mathrm{~N}$. Salts solution composition is $\mathrm{MnSO}_{4} \cdot \mathrm{H}_{2} \mathrm{O} 1.3 \mathrm{~g} \cdot \mathrm{L}^{-1}, \mathrm{ZnCl}_{2} 0.40 \mathrm{~g} \cdot \mathrm{L}^{-1}, \mathrm{Na}_{2} \mathrm{MoO}_{4} \cdot 2 \mathrm{H}_{2} \mathrm{O} 0.28 \mathrm{~g} \cdot \mathrm{L}^{-1}, \mathrm{H}_{3} \mathrm{BO}_{3} 0.06$ $\mathrm{g} \cdot \mathrm{L}^{-1}, \mathrm{NH}_{4} \mathrm{Cl} 10 \mathrm{~g} \cdot \mathrm{L}^{-1}, \mathrm{CoCl}_{2} \cdot 6 \mathrm{H}_{2} \mathrm{O} 0.66 \mathrm{~g} \cdot \mathrm{L}^{-1}, \mathrm{CaCl}_{2} \cdot 2 \mathrm{H}_{2} \mathrm{O} 2.0 \mathrm{~g} \cdot \mathrm{L}^{-1}, \mathrm{CuSO}_{4} \cdot 5 \mathrm{H}_{2} \mathrm{O} 0.46 \mathrm{~g} \cdot \mathrm{L}^{-1}$.

Fed-batch cultivations were performed using a $400 \mathrm{~g} \cdot \mathrm{L}^{-1}$ glucose solution as carbon source and a $120 \mathrm{~g} \cdot \mathrm{L}^{-1}$ ammonium sulphate solution as nitrogen source. For the experiment with increased calcium addition, $10 \mathrm{~g} \cdot \mathrm{L}^{-1}$ calcium nitrate was added to the $400 \mathrm{~g} \cdot \mathrm{L}^{-1}$ glucose solution.

\subsection{Inoculum Preparation}

A $100 \mathrm{~mL}$ shake flask containing $20 \mathrm{~mL}$ of complete chemically defined medium was inoculated with one cryovial of $B$. subtilis from the frozen stock. The seeded culture was incubated at $37^{\circ} \mathrm{C}$ and $150 \mathrm{rpm}$ on a rotary shaker (Innova 4330, New Brunswick Scientific Co. Inc., USA) for 28 hours to a final optical density (595 nm) of approximately 8.0. The cells were then used to inoculate the 2-L bioreactor at an inoculum size of $1 \%(\mathrm{v} / \mathrm{v})$.

\subsection{Shake Flask Cultivation}

Experiments were conducted in $500 \mathrm{~mL}$ shake flasks with $50 \mathrm{~mL}$ of chemically defined medium inoculated with $500 \mu \mathrm{L}$ of a spore suspension (optical density at $595 \mathrm{~nm}$ of approximately 8.0). The cultures were incubated at $37^{\circ} \mathrm{C}$ on a rotary shaker at $150 \mathrm{rpm}$ for 48 hours.

\subsection{Batch Bioprocess}

A 2-L bioreactor (Biostat B, B. Braun, Germany) was inoculated with $20 \mathrm{~mL}$ of seed culture for a final volume of $2 \mathrm{~L}$. Cultivation temperature and aeration rate were maintained constant at $37^{\circ} \mathrm{C}$ and $2 \mathrm{~L} \cdot \mathrm{min}^{-1}$, respectively. The dissolved oxygen concentration was controlled at $30 \%$ by varying the agitation rate between $100-1200 \mathrm{rpm}$. Cultivation $\mathrm{pH}$ was controlled above 6.5 with the addition of $\mathrm{NaOH} 2 \mathrm{M}$. Whenever necessary an antifoaming agent (SAG 471, $0.5 \mathrm{~g} \cdot \mathrm{L}^{-1}$, Crompton Co., USA) was automatically added to the bioreactor.

\subsection{Fed-Batch Bioprocess}

A 2-L bioreactor (Biostat B, B. Braun, Germany) was inoculated with $20 \mathrm{~mL}$ of seed culture. Cultivation conditions were controlled as described for the batch bioprocess and the cultivation was initiated with $1.2 \mathrm{~L}$ of complete chemically defined media. The bioreaction was conducted divided into three stages: batch culture for the first 12 hours, fed-batch for the next 4 hours and finally batch culture until the end of the cultivation for a total bioreaction duration of approximately 60 hours. At the middle of the exponential growth phase, the nutrient feeding was initiated. Approximately $234 \mathrm{~g}$ and $108 \mathrm{~g}$ of glucose and ammonium sulphate feeding solutions were added using an exponential and constant feeding profile $\left(Q=30 \mathrm{~g} \cdot \mathrm{h}^{-1}\right)$, respectively. The exponential feeding rate profile was determined using simple mass balances based on a Monod-type kinetic model, as described in [11].

$$
X=X_{0} e^{\mu . t}
$$

where $X$ is the biomass concentration $\left(\mathrm{g} \cdot \mathrm{l}^{-1}\right)$; $X_{0}$ is the biomass concentration at the beginning of the fed-batch phase $\left(\mathrm{g} \cdot \mathrm{l}^{-1}\right) ; \mu$ is the specific growth rate $\left(\mathrm{h}^{-1}\right)$ and $t$ is the time length of the bioreaction (h).

Considering constant specific glucose consumption, a constant glucose concentration in the cultivation medium was achieved by feeding the concentrated glucose solution according to the following equation: 


$$
Q=Q_{0} e^{\mu . t}
$$

where $Q$ is the feeding solution flow rate and $Q_{0}$ is the feeding solution flow rate at the beginning of the fedbatch phase $\left(\mathrm{g} \cdot \mathrm{h}^{-1}\right)$. The kinetic parameters as $Q_{0}=15 \mathrm{~g} \cdot \mathrm{h}^{-1}$ and $\mu=0.5 \mathrm{~h}^{-1}$ were determined from batch experiments (data not shown).

In the fed-batch with the addition of nitrogen, glucose and calcium, after the initial fed-batch phase of 4 hours a resting period of approximately 45 min was given to allow glucose levels to decrease and only after that a second feeding phase was initiated. In this second fed-batch phase a solution containing glucose and calcium was added. A constant feeding profile was used for $2 \mathrm{~h}\left(Q=13 \mathrm{~g} \cdot \mathrm{h}^{-1}\right)$. After this period a decreasing feeding profile was used to match the decreasing carbon source demand due to the sporulation process $(Q=-3.6 t+13)$.

Data acquisition and process control were implemented using the Universal Bio-Process Control SystemUBICON (Electronic System Design, Hannover, Germany).

\subsection{Glucose Determination}

One milliliter of culture medium was clarified by centrifugation at $14,000 \mathrm{~g}$ for 5 minutes. Glucose concentration in the supernatant was determined using an enzymatic test (Glucose HK, Sigma Diagnostics).

\subsection{Nitrogen Determination}

Two milliliters of culture medium were clarified by centrifugation at 14,000 g for 5 minutes. Ammonium concentration in the supernatant was determined using the Kjeldhal method [15].

\subsection{Cell Growth Determination}

Cell growth was monitored by measuring the optical density (OD) at $595 \mathrm{~nm}$. Whenever necessary samples were diluted to a final OD value lower than 0.5 .

\subsection{Determination of Vegetative Cells and Spores Concentrations}

Serial dilutions of the cell suspension to be tested were prepared and $10 \mu \mathrm{L}$ of each dilution were inoculated to a 96 wells plate containing $180 \mu \mathrm{L}$ of LB media. For each dilution 10 replicates were prepared. Plates were incubated at $37^{\circ} \mathrm{C}$ for 24 hours and cell concentration was determined using the Reed and Muench Method [16]. Spores were counted using the same method, but the plates were heated to $80^{\circ} \mathrm{C}$ for 20 minutes before incubation.

\subsection{Sporulation Efficacy and Spore Fraction}

Sporulation efficacy was defined as the percentage of the vegetative cells that undergo a complete sporulation process yielding heat resistant spores, and was calculated as the ratio between the spore titre and the maximum of the vegetative cell titre reached during the bioreaction. The spore fraction was defined as the percentage of spores at a given time and was calculated as the ratio between spore concentration and total cell concentration (spores and vegetative cells) in each sample.

\section{Results and Discussion}

\subsection{Shake Flask Experiments}

In order to determine the most effective medium for Bacillus subtilis spore production several chemically defined media formulations were tested in shake flask cultivations and compared with the standard complex media used for spore production (Difco Sporulation Media, DSM, Difco, USA) (Figure 1).

Media \#1, 3 and 4 consisted mainly of salts with glucose, glycerol or both. Media \#2, 5, 6 and 7 was composed of salts and different carbon sources: citric acid and glucose, glycerol or both. The results indicate that in all the experiments carried out using chemically defined media spore production was lower than in the experiment carried out using DSM. Within the experiments performed with chemically defined media the best results were obtained using media formulation \#2, with higher carbon and nitrogen concentration. This media formulation was optimized by studying the influence of vitamin, nitrogen, carbon and calcium concentration on spore 


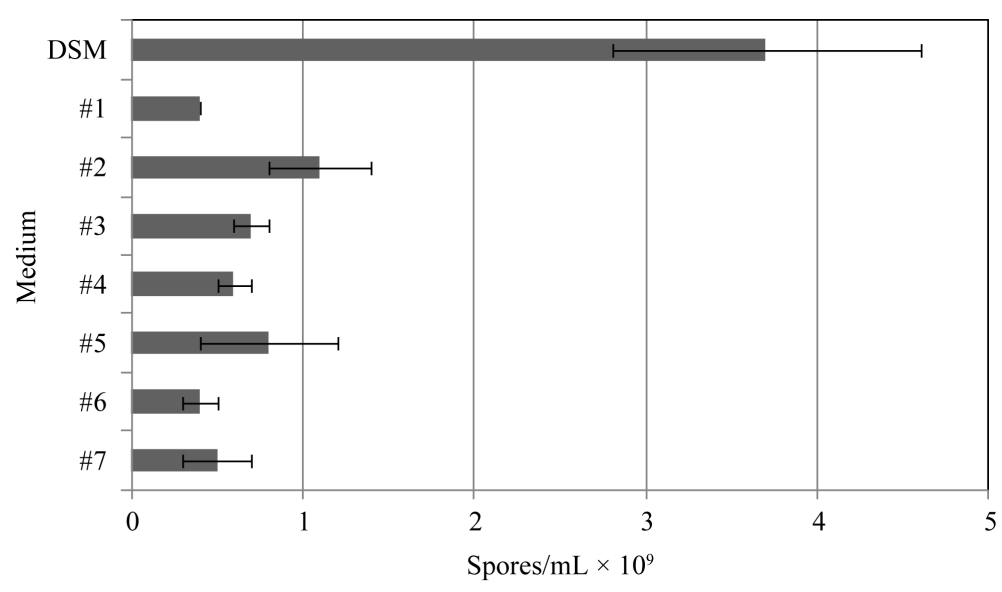

Figure 1. Maximum spore production achieved 48 hours after inoculation using several media formulations (DSM-Difco sporulation medium; \#1 to \#7-Chemically defined media formulations). The data are presented as arithmetic means \pm standard deviations.

production. For these experiments one nutrient concentration was changed while keeping constant the remaining media composition, permitting to achieve the optimum media composition.

Vitamins are essential for sporulation. Previous experiments performed using the sporulating fungi Coniothyrium minitans indicate that thiamine is the most critical vitamin for sporulation. Without this vitamin no sporulation occurs [17]. In this study a mixture of several vitamins was tested and the results were compared with the results obtained using only thiamine (Figure 2(a)). It was observed that the spore yield obtained using 10 $\mathrm{mg} \cdot \mathrm{L}^{-1}$ of thiamine was similar to the result obtained using the vitamin cocktail, which is advantageous since it is less expensive and it is easier to prepare.

Ammonium sulphate and ammonium hydrogen phosphate were tested as the main nitrogen sources (Figure 2(b)). The results show that spore production increased with the increase of ammonium concentration, the highest spore production being obtained using a mixture of both ammonium sources. This result may be explained by inhibitory effects of sulphate, or by the increased phosphate availability in the sporulation stage or by a combination of both factors.

Glucose was used as the main carbon source. Spore production increased with the increase of glucose concentration up to $20 \mathrm{~g} \cdot \mathrm{L}^{-1}$ (Figure 2(c)). The inhibitory effects of glucose over sporulation were only observed for glucose concentrations above $20 \mathrm{~g} \cdot \mathrm{L}^{-1}$.

Calcium ion is a major constituent of the spore coat. Cells are strongly dependent of the addition of this ion to achieve maximal sporulation. The effect of calcium ion concentration was studied within the range of 0.4 to 1.2 $\mathrm{g} \cdot \mathrm{L}^{-1}$ and it was observed that spore production increased with the increase of calcium concentration up to 0.6 g. $\mathrm{L}^{-1}$ (Figure 2(d)).

\subsection{Bioreactor Batch Experiments}

Cultivation was performed using the optimized chemically defined media formulation. During the exponential growth phase of the $B$. subtilis batch cultivation performed at 2-L bioreaction scale the agitation rate increased from 100 to approximately $1200 \mathrm{rpm}$ to compensate for the oxygen consumption rate (Figure 3(a)). The results depicted in Figure 3(b) and Figure 3(c) show that the maximum vegetative cell concentration $\left(1.3 \times 10^{10}\right.$ cells $/ \mathrm{mL}$ ) was obtained at the end of the exponential growth phase but after that a high cell lysis was observed and only $48 \%$ of the vegetative cells gave rise to heat resistant spores, the final spore concentration being $6.3 \times$ $10^{9}$ spores $/ \mathrm{mL}$.

\subsection{Bioreactor Fed-Batch Experiments}

A fed-batch bioprocess similar to that used in Monteiro et al. 2005 was used to increase spore production of $B$. subtilis. The main objective was to maintain the C:N ratio (10:1) in both batch and fed-batch phases. To avoid 

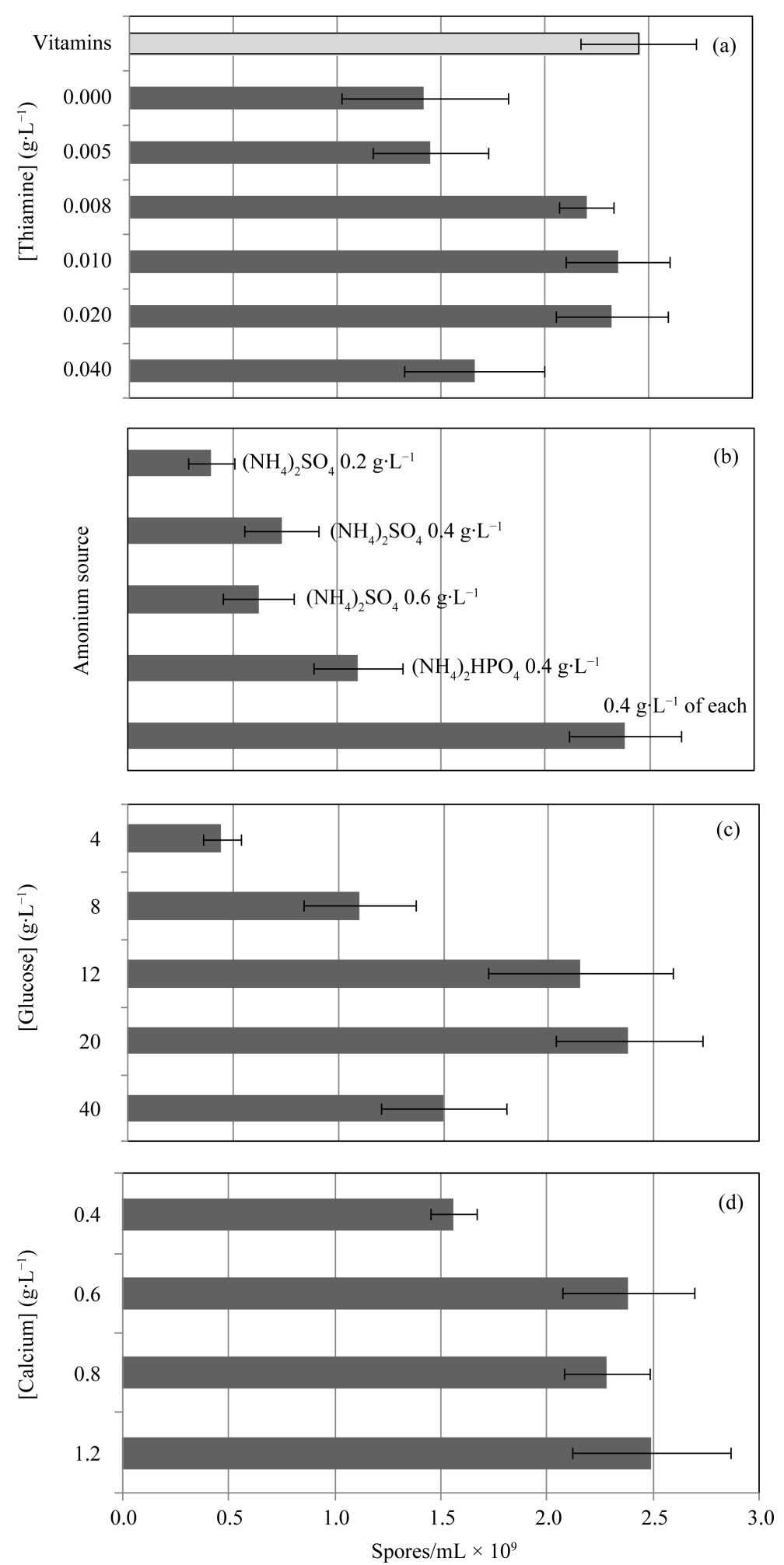

Figure 2. Spore production 48 hours after inoculation: (a) maximum spore production using a vitamin cocktail $(\square)$ versus different thiamine concentrations (ם); (b) effect of ammonium source concentration; (c) effect of glucose concentration; (d) effect of calcium concentration. The data are presented as arithmetic means \pm standard deviations. 

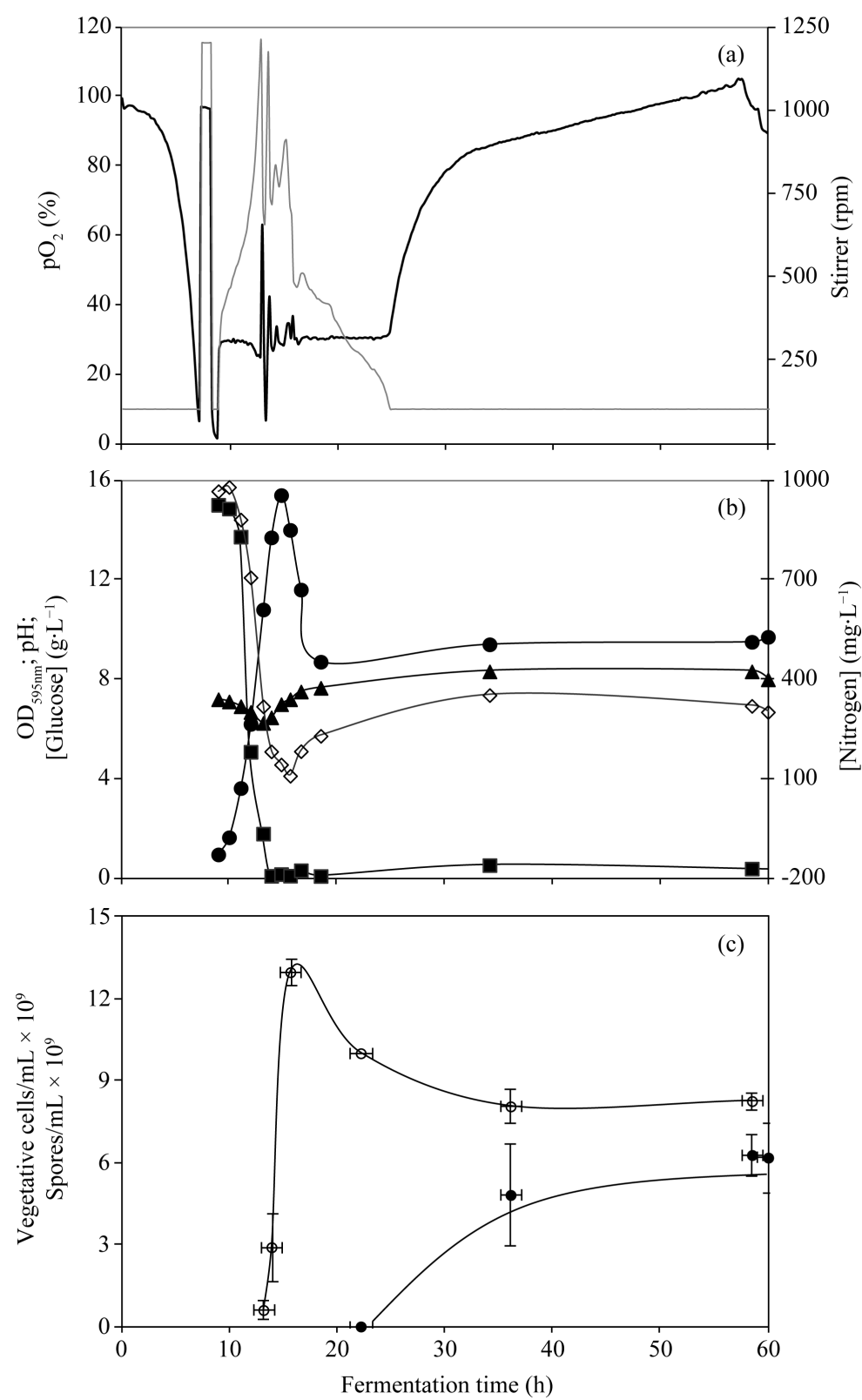

Figure 3. Batch cultivation using the optimized synthetic media formulation: (a) ( _ ) $\mathrm{pO}_{2}$ (\%); (-) stirrer (rpm); (b) (•) optical density at $595 \mathrm{~nm} ;(\boldsymbol{\Delta}) \mathrm{pH}$; (घ) glucose concentration $\left(\mathrm{g} \cdot \mathrm{L}^{-1}\right)$; $(\diamond)$ nitrogen concentration $\left(\mathrm{mg} \cdot \mathrm{L}^{-1}\right)$; (c) $(\mathrm{O})$ vegetative cell concentration (cells/mL); $(\bullet)$ spore concentration (spores/ $\mathrm{mL}$ ). Error bars represent standard deviations.

the inhibitory effects of carbon and nitrogen sources over sporulation, an exponential and a constant feeding profile were used for glucose and ammonium, respectively. Calcium was also added under fed-batch mode, as precipitation occurs when concentration higher than $0.6 \mathrm{~g} \cdot \mathrm{L}^{-1}$ is used in the preparation of the fermentation media.

\subsubsection{Effect of Glucose and Nitrogen Concentration at the End of the Growth Phase}

In the batch experiments, glucose and ammonium were depleted at the end of the exponential growth phase (Figure 3(b)) and a high cell lysis was observed. One fed-batch experiment was carried out without both glucose and ammonium at the end of the exponential growth phase and a high cell lysis was observed (experiment 
1). To investigate if lysis was due to nutrients depletion (carbon or ammonium) two experiments were performed: experiment 2 and 3 with the addition at the end of the exponential phase of glucose and ammonium, respectively. The results, shown in Figure 4 and Table 1, indicate that glucose is totally consumed and ammonium accumulates in the media. Glucose is required for the sporulation stage, avoiding the autolytic tendencies of the cells at the end of the exponential growth phase, in accordance with published data by [12] and [13].

In the experiment with residual glucose addition during part of the stationary phase (experiment 2), despite a maximum vegetative cell concentration lower than in the other experiments, due to a lower glucose addition during the exponential growth phase, a higher sporulation efficacy was reached (approximately 31\%) leading to a final spore concentration of $2.6 \times 10^{10}$ spores $/ \mathrm{mL}$. This higher efficacy indicates that for the sporulation process both, nitrogen and glucose levels must be low to avoid cell lysis, although it is also necessary to supply glucose to the culture permitting enough energy for the sporulation process to be completed.

\subsubsection{Effect of Calcium Addition}

Using the chemically defined medium developed here it was observed that calcium ion plays a critical role in the sporulation process, large quantities of this ion being required for maximal sporulation.

As for high calcium concentrations precipitation occurs in the cultivation media, this element was also added in the fed-batch mode: an experiment was performed with the addition of both glucose and calcium $\left(400 \mathrm{~g} \cdot \mathrm{L}^{-1}\right.$ and $10 \mathrm{~g} \cdot \mathrm{L}^{-1}$, respectively). The fed-batch bioprocess allowed a high density of vegetative cells being obtained. Glucose addition at the end of the growth phase to prevent the autolysis permitted to have a large vegetative cell concentration for sporulation. To accommodate the high calcium demand for the complete sporulation of the vegetative cells produced, calcium nitrate was added to the bioreactor in fed-batch mode.

The feeding profiles used for the addition of nitrogen, carbon and calcium to the bioreactor were able to keep the optimum nutrient balance throughout the all bioreaction (Figure 5(b)): at the end of the growth phase only residual levels of glucose and low nitrogen concentration were present in the culture media; during all the feeding phase both glucose and nitrogen levels were kept below $20 \mathrm{~g} \cdot \mathrm{L}^{-1}$ and $900 \mathrm{mg} \cdot \mathrm{L}^{-1}$, respectively (Figure 5(a));

Table 1. Effect of glucose and nitrogen concentration at the end of the exponential phase.

\begin{tabular}{ccccc}
\hline & $\begin{array}{c}\text { Max. vegetative cell conc. } \\
\text { (cell/mL) }\end{array}$ & $\begin{array}{c}\text { Spore Conc. } \\
(\text { spore/mL) }\end{array}$ & Sporulation efficacy (\%) & Spore Fraction (\%) \\
\hline Experiment 1 & $1.44 \times 10^{11}$ & $1.25 \times 10^{10}$ & 8.7 & 100 \\
Experiment 2 & $8.3 \times 10^{10}$ & $2.6 \times 10^{10}$ & 31.3 & 90 \\
Experiment 3 & $1.48 \times 10^{11}$ & $3.5 \times 10^{9}$ & 2.4 & 74 \\
\hline
\end{tabular}

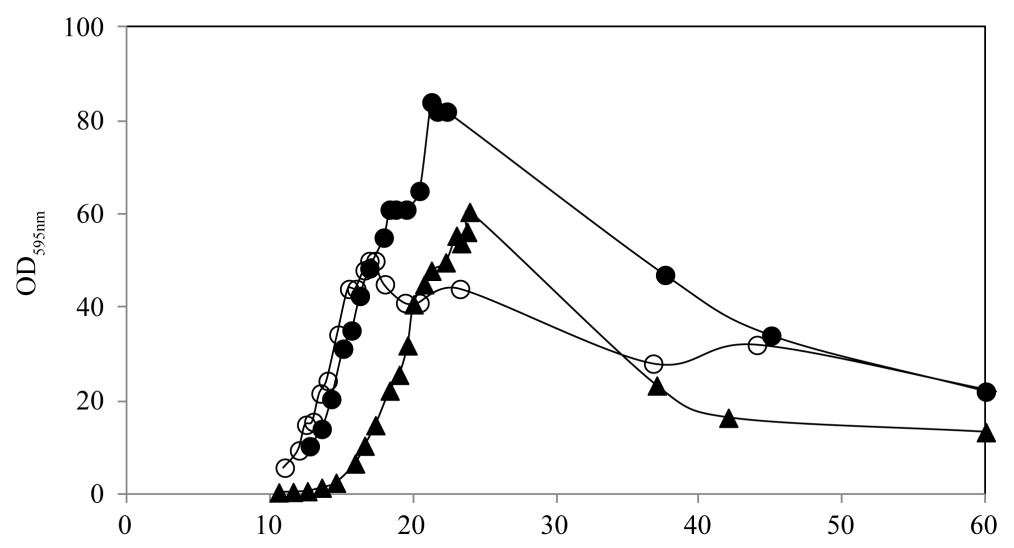

Figure 4. Fed-batch cultivations of Bacillus subtilis to study the effect of glucose and nitrogen concentration at the end of the exponential growth phase: $(\bullet)$ addition of nitrogen at the end of the exponential growth phase; $(\boldsymbol{\Delta})$ residual levels of nitrogen and glucose at the end of the exponential growth phase; $(O)$ glucose addition during the first hours of the stationary phase. 

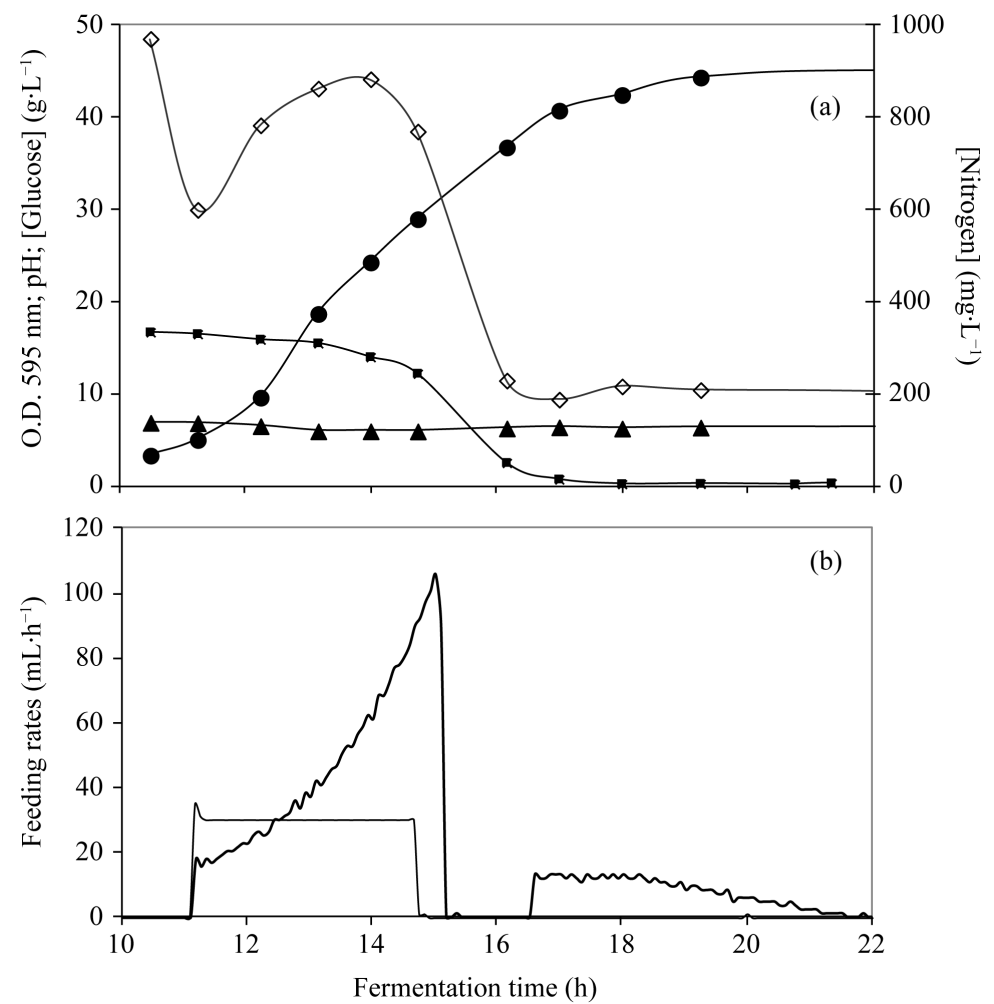

Figure 5. Fed-batch cultivation of Bacillus subtilis: (a) (•) optical density at $595 \mathrm{~nm} ;(\boldsymbol{\Delta}) \mathrm{pH} ;(\boldsymbol{\square})$ glucose concentration $\left(\mathrm{g} \cdot \mathrm{L}^{-1}\right) ;(\diamond)$ nitrogen concentration (mg $\left.\cdot \mathrm{L}^{-1}\right)$; (b) Feeding rates: ( ) glucose and calcium; (-) nitrogen.

during the onset of sporulation glucose addition was controlled to avoid accumulation of glucose in the bioreactor but providing the required amounts for sporulation.

With this methodology it was possible to fulfill the main objectives of this work: high cell growth during the exponential growth phase was obtained; cell lysis was avoided; optimal sporulation conditions were created allowing almost all the vegetative cells to sporulate, to a final spore concentration of $3.6 \times 10^{10} \mathrm{spores} / \mathrm{mL}$. In the future the kinetic parameters used in these experiments should be optimized.

\section{Conclusions}

In this study the composition of a chemically defined medium, free of animal origin components, was optimized in terms of vitamin, nitrogen, carbon and calcium concentration to maximize sporulation efficacy. Batch experiments using this media formulation conduced to an increase of the volumetric spore productivity permitting to reach a final spore concentration of $6.3 \times 10^{9}$ spores $/ \mathrm{mL}$.

Using this chemically defined medium, it was possible to achieve better sporulation than that with standard Difco Sporulation Medium (DSM) both in batch and fed-batch bioreactions.

Fed-batch experiments conducted using different C:N ratios at the end of the exponential growth phase, indicated that the excess of glucose over ammonium minimizes the autolytic tendencies of the cells at the end of the exponential growth phase. There is experimental support to suggest that autolysis occurs after brief starvation for a carbon source. Electron-donating agents are effective in retarding autolysis. The loss of either the electrical potential or the proton gradient across the $B$. subtilis membrane results in a change in either the structure of the membrane or the surface chemistry of the cell [12].

To increase spore production a controlled bioprocess comprising an initial and a final batch phases and an intermediate fed-batch operation was used. With this fed-batch approach, using the developed chemically defined medium, it was possible to obtain a high cell growth during the exponential growth phase and to avoid cell lysis, allowing almost all the vegetative cells to sporulate, to a final spore concentration of $3.6 \times 10^{10} \mathrm{spores} / \mathrm{mL}$, and 
the highest reported value for $B$. subtilis spore production. The concentration of spores reported in the literature varies enormously being the highest values $7.0 \times 10^{9}$ spores $/ \mathrm{mL}$ and $7.4 \times 10^{9}$ spores $/ \mathrm{mL}$, obtained by [18] and [11], respectively.

\section{Acknowledgements}

This work was supported by the European Commission project "Spore Probiotics: An Alternative to Antibiotics” (QLK-CT-2001-01729).

\section{References}

[1] Oliveira, J.E., Van der Hoeven-Hangoor, E., Van der Linde, I.B., Montijn, R.C. and Van der Vossen, J.M. (2014) In Ovo Inoculation of Chicken Embryos with Probiotic Bacteria and Its Effect on Posthatch Salmonella Susceptibility. Poultry Science, 93, 818-829. http://dx.doi.org/10.3382/ps.2013-03409

[2] Manabe, K., Kageyama, Y., Morimoto, T., Shimizu, E., Takahashi, H., Kanaya, S., Ara, K., Ozaki, K. and Ogasawara, N. (2013) Improved Production of Secreted Heterologous Enzyme in Bacillus subtilis Strain MGB874 via Modification of Glutamate Metabolism and Growth Conditions. Microbial Cell Factories, 12, 18. http://dx.doi.org/10.1186/1475-2859-12-18

[3] Veenig, J.W., Smits, W.K., Hamoen, L.W. and Kuipers, O.P. (2006) Single Cell Analysis of Gene Expression Patterns of Competence Development and Initiation of Sporulation in Bacillus subtilis Grown on Chemically Defined Media. Journal of Applied Microbiology, 101, 531-541. http://dx.doi.org/10.1111/j.1365-2672.2006.02911.X

[4] Yu, X., Hallett, S.G., Sheppard, J. and Watson, A.K. (1998) Effects of Carbon Concentration and Carbon-to-Nitrogen Ratio on Growth, Conidiation, Spore Germination and Efficacy of the Potential Bioherbicide Colletotrichum coccodes. Journal of Industrial Microbiology and Biotechnology, 20, 333-338. http://dx.doi.org/10.1038/sj.jim.2900534

[5] Fisher, S.H. (1999) Regulation of Nitrogen Metabolism in Bacillus subtilis Vive la Différence! Molecular Microbiology, 32, 223-232. http://dx.doi.org/10.1046/j.1365-2958.1999.01333.x

[6] Carvalho, A.L.U., Oliveira, F.H.P.C., Mariano, R.L.R., Gouveia, E.R. and Souto-Maior, A.M. (2010) Growth, Sporulation and Production of Bioactive Compounds by Bacillus subtilis R14. Brazilian Archives of Biology and Technology, 53, 643-652. http://dx.doi.org/10.1590/S1516-89132010000300020

[7] Dauner, M., Storni, T. and Sauer, U. (2001) Bacillus subtilis Metabolism and Energetics in Carbon-Limited and Excess-Carbon Chemostat Culture. Journal of Bacteriology, 183, 7308-7317. http://dx.doi.org/10.1128/JB.183.24.7308-7317.2001

[8] Slieman, T.A. and Nicholson, W.L. (2001) Role of Dipicolinic Acid in Survival of Bacillus subtilis Spores Exposed to Artificial an Solar UV Radiation. Applied and Environmental Microbiology, 67, 1274-1279. http://dx.doi.org/10.1128/AEM.67.3.1274-1279.2001

[9] O’Hara, M.B. and Hageman, J. (1990) Energy and Calcium Ion Dependence of Proteolysis during Sporulation of Bacillus subtilis Cells. Journal of Bacteriology, 172, 4161-4170.

[10] Hauser, P.M. and Errington, J. (1995) Characterization of Cell Cycle Events during the Onset of Sporulation in Bacillus subtilis. Journal of Bacteriology, 177, 3923-3932.

[11] Monteiro, S.M.S., Clemente, J.J., Henriques, A.O., Gomes, R.G., Carrondo, M.J.T. and Cunha, A.E. (2005) A Procedure for High-Yield Spore Production by Bacillus subtilis. Biotechnology Progress, 21, 1026-1031. http://dx.doi.org/10.1021/bp050062z

[12] Jolliffe, L.K., Doyle, R.J. and Streips, U.N. (1981) The Energized Membrane and Cellular Autolysis in Bacillus subtilis. Cell, 25, 753-763. http://dx.doi.org/10.1016/0092-8674(81)90183-5

[13] Hu, P., Leighton, T., Ishkhanova, G. and Kustu, S. (1999) Sensing of Nitrogen Limitation by Bacillus subtilis: Comparison to Enteric Bacteria. Journal of Bacteriology, 181, 5042-5050.

[14] Barbosa, T.M., Serra, C.R., la Regione, R., Woodward, M.J. and Henriques, A.O. (2005) Screening for Bacillus Isolates in the Broiler Gastrointestinal Tract. Applied and Environmental Microbiology, 71, 968-978. http://dx.doi.org/10.1128/AEM.71.2.968-978.2005

[15] Jernejc, K., Cimerman, A. and Perdih, A. (1986) Comparison of Different Methods for Protein Determination in Aspergillus niger Mycelium. Applied Microbiology and Biotechnology, 23, 445-448. http://dx.doi.org/10.1007/BF02346058

[16] Reed, L.J. and Muench, H.A. (1938) Simple Method for Estimating Fifty Percent Endpoints. The American Journal of Hygiene, 27, 493-497.

[17] Ooijkass, L.P., Wilkinson, E.C., Tramper, J. and Buitelaar, R.M. (1998) Medium Optimization for Spore Production of 
Coniothyrium minitans Using Statistically_Based Experimental Designs. Biotechnology and Bioengineering, 64, 92100.

[18] Tavares, M.B., Souza, R.D., Luiz, W.B., Cavalcante, R.C.M., Casaroli, C., Martins, E.G., Ferreira, R.C.C. and Ferreira, L.C.S. (2013) Bacillus subtilis Endospores at High Purity and Recovery Yields: Optimization of Growth Conditions and Purification Method. Current Microbiology, 66, 279-285. http://dx.doi.org/10.1007/s00284-012-0269-2 